\title{
EXPERIMENTAL STUDY ON SURFACE/SUBSURFACE WATER EXCHANGE IN ALTERNATE SANDBAR
}

\author{
XI Qing ${ }^{1}$, Tetsuya SUMI $^{2}$ and Tetsuro TSUJIMOTO ${ }^{3}$ \\ ${ }^{1}$ Student Member of JSCE, Doctoral Student, Dept. of Civil Engineering, Nagoya University \\ (Furo-cho, Chikusa-ku, Nagoya 464-8603, Japan) \\ ${ }^{2}$ Member of JSCE, Dr. of Eng., Lecturer, Dept. of Civil Engineering, Nagoya University \\ ${ }^{3}$ Member of JSCE, Dr. of Eng., Professor, Dept. of Civil Engineering, Nagoya University
}

\begin{abstract}
The tendency in river management is to become more integrated in fluvial fan. Especially, the interaction of the surface and subsurface flow should be considered. The pool-riffle-pool sequences in a river with alternate sandbars govern the surface water profile and also subsurface flow in the river. Surface water flow usually changes near the alternate sandbar with high permeability due to the interaction of surface and subsurface flow. The study on the relationship of the upstream total discharge, the required minimum discharge for certain purpose (such as fishery, navigation), and the amount of leakage from surface to subsurface becomes very significant in the river management. As the initial framework, this problem is discussed in a river reach scale in this study. The required environmental discharge is assumed to be the minimum surface flow, and the relationship between leaking flux and the required upstream total discharge is discussed based on the result of flume experiment.
\end{abstract}

Key Words: environmental discharge, surface flow leakage, interaction, subsurface water, alternate sandbar, pool and riffle structure, bed shape, bed amplitude, flume experiment.

\section{INTRODUCTION}

When we consider water management in downstream river under low flow condition, two techniques are needed; (1) determination of required minimum surface water discharge or environmental preservation discharge, (2) evaluation of leaking or exchanging flux between surface water and subsurface water (groundwater).

In general on (2), the factors that affect flow exchange between channels and alternate bars include bed geometry (amplitude and wavelength of sandbar, channel slope, channel width) and hydraulic properties $\left(\right.$ Freeze $\left.^{1) 2}\right)$. Studies on interaction problem were conducted mainly in mountainous stream at downstream region from dams and downstream segment area including alluvial fan. Harada and Takagi ${ }^{3}$ ) studied this problem in mountainous channel analytically and some geomorphological features including valley width have a strong effect on subsurface water flux distribution and surface water depth. In alluvial fan, Larkin $^{4)}$ showed that channel slope, channel width and sinuosity are related to penetration rate into the aquifer. Harada et al. ${ }^{5)}$ showed the water interaction in Yasu River by field investigation and numerical analysis. Recent studies in segment scale have been developing total analysis model including water interaction.

On the other hand, at the local scale viewpoint, especially reach scale including pool-riffle and sand bar in mid-stream or downstream segment, some cross-sections with severe hydraulic condition (small surface water discharge, small depth and so on) can be seen under low flow condition. Recently subsurface flow patterns in sandbars are investigated by using installed wells ${ }^{6}$ ) and results show that water level difference between two pools leads to leakage into sandbar and outflow from sandbar to downstream pool. Ahmed et al. ${ }^{7)}$ studied interactions between surface and subsurface water in a stream with alternate sandbar by experiment and numerical simulation in horizontal 2-D. His study evaluated exchange rate between "surface flow area" and "sandbar area" from ecological viewpoint. But for water management and evaluation of required total upstream discharge, this method is not applicable, because subsurface water in substrate 

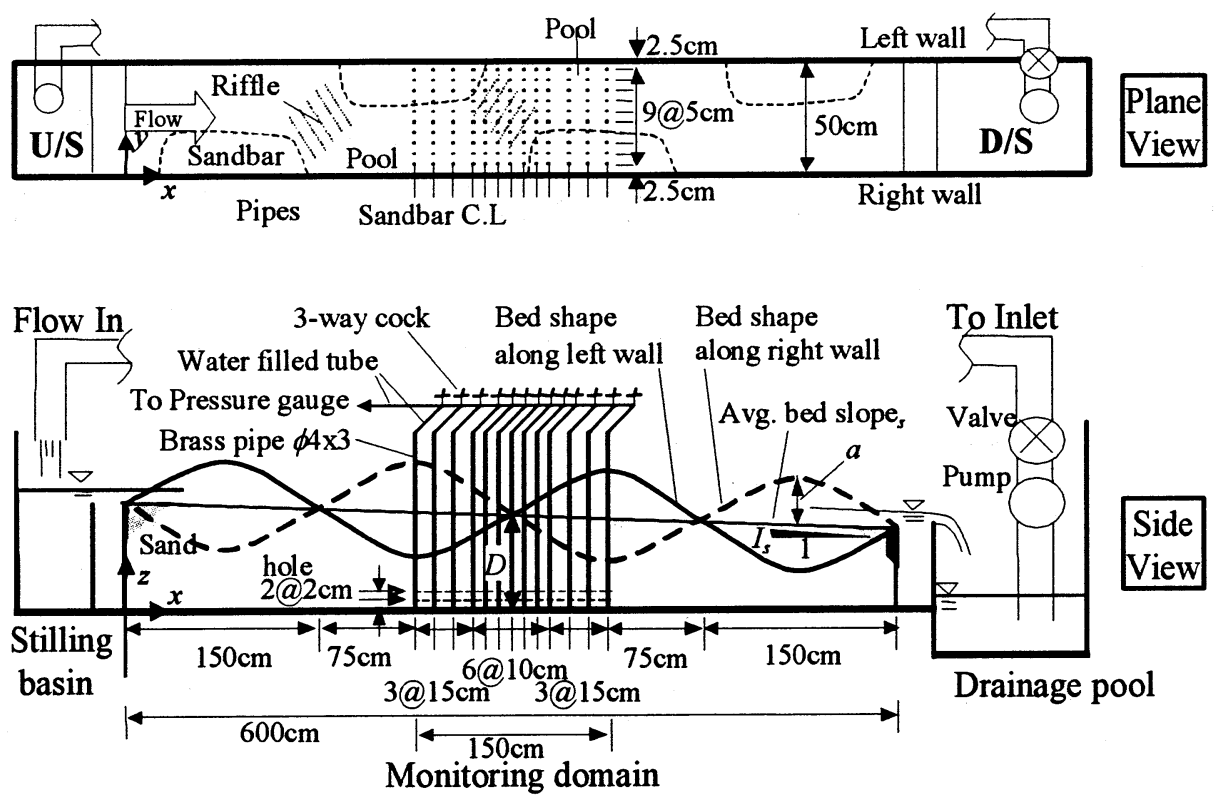

Fig. 1 Experiment setup

Table 1 Experimental conditions

\begin{tabular}{|c|c|c|c|c|c|c|c|c|c|c|}
\hline \multicolumn{5}{|c|}{ Bed condition } & \multicolumn{6}{|c|}{ Run No } \\
\hline$I_{s}$ & $\begin{array}{c}B \\
(\mathrm{~cm})\end{array}$ & $\begin{array}{c}D \\
(\mathrm{~cm})\end{array}$ & $\begin{array}{c}\lambda \\
(\mathrm{cm})\end{array}$ & $\begin{array}{c}a \\
(\mathrm{~cm})\end{array}$ & \multicolumn{6}{|c|}{ Discharge, $Q\left(\mathrm{~cm}^{3} / \mathrm{s}\right)$} \\
\hline \multirow{6}{*}{$1 / 100$} & \multirow{6}{*}{50} & \multirow{6}{*}{15} & \multirow{6}{*}{300} & \multirow{2}{*}{4.2} & case1-1 & case1-2 & case $1-3$ & case $1-4$ & case $1-5$ & case $1-6$ \\
\hline & & & & & 1624 & 899 & 504 & 346 & 114 & 60.7 \\
\hline & & & & \multirow{2}{*}{6.3} & case $2-1$ & case $2-2$ & case $2-3$ & case $2-4$ & case $2-5$ & case $2-6$ \\
\hline & & & & & 1611 & 886 & 516 & 348 & 123 & 60.7 \\
\hline & & & & \multirow{2}{*}{8.4} & case $3-1$ & case $3-2$ & case $3-3$ & case $3-4$ & case $3-5$ & case $3-6$ \\
\hline & & & & & 1624 & 900 & 500 & 350 & 180 & 100 \\
\hline
\end{tabular}

under surface water is treated as surface water. In this study, total flux of surface and subsurface water component through arbitrary cross-section is evaluated in cross-sectional flow area of respective water component.

\section{OBJECTIVE AND SCOPE OF THE STUDY}

In this study, flume experiment is conducted for following objectives;

- To get subsurface flow characteristics for some typical surface water profiles generated by several different given discharges and pool and riffle features with low channel flow conditions.

- To discuss the characteristics of longitudinal profile of total subsurface water flux through sand bed from cross-sectional view point, and discuss its deterministic factors in variable given discharge and bed shape conditions.

- Finally to get the relationship among "surface water/ subsurface water exchange rate," the total discharge and sand bed amplitude.

\section{EXPERIMENT}

\section{(1) Experiment setup}

The experiment set-up is shown in Fig.1. A glass-side horizontal flume with a length $\left(L_{f}\right)$ of $600 \mathrm{~cm}$ and a width $\left(B_{f}\right)$ of $50 \mathrm{~cm}$ is used. A pump circulated the steady state discharge, and a stilling basin installed at the upstream provided uniform flow at entrance in the flume.

Uniform sand with a median diameter of $2.1 \mathrm{~mm}$ is used for preparation of streambed and sandbar. Hydraulic conductivity of this sand $k=4.96 \mathrm{~cm} / \mathrm{s}$ is previously obtained by falling head method. The bed was moulded for each bed shape condition and 
the sandbars are reproduced according to their shape and location. The bed elevation $\left(z_{b}\right)$ are given according to the eq.(1).

$$
z_{b}(x, y)=z_{\text {bave }}-\left(x-\frac{L_{f}}{2}\right) I_{s}+a \sin \frac{2 \pi x}{\lambda} \cos \frac{\pi y}{B_{f}}
$$

where, $I_{s}$ is the longitudinal slope of the flume bed. The average thickness $\left(z_{\text {bave }}\right)$ of the permeable layer, sandbar wavelength $(\lambda)$ and width of the flume $\left(B_{f}\right)$ are taken as $15 \mathrm{~cm}, 300 \mathrm{~cm}$ and $50 \mathrm{~cm}$ respectively. Three different bed amplitudes $(a)$ are taken for the individual cases. Bed surface over riffle area parts are covered by stainless wire mesh with $5 \mathrm{~mm}$ holes, on which sand particles are glued ensuring no sediment transport in the flume bed and no effect to permeability.

Monitoring domain is set over whole width and $1.5 \mathrm{~m}$ length at flume center. In this domain, surface water flow moves from right hand side to left hand side and the riffles are centered in the flume, so that interaction between surface water and subsurface water is expected in the center area of the domain. 130 brass tubes (outer diameter $4 \mathrm{~mm}$ ) are inserted into the sand bed over the whole monitoring domain in order to measure the piezometric head of the subsurface flow. All tubes are connected to one pressure gauge (sensitivity is $0.1 \mathrm{~mm}$ in head) by water-filled-tubes and three-way-cock and monitoring pipes are selected by cock operation. Small holes are made on the tubes at the position $z=0,2$ and $4 \mathrm{~cm}$ to measure the piezometric head. Under Dupuit-Forchheimer assumption, measured piezometric heads represent head of whole vertical position and subsurface water (groundwater) level at current horizontal position. In the central part, transverse and longitudinal intervals of pipes are $5 \mathrm{~cm}$ and $10 \mathrm{~cm}$. The transverse interval changes to $15 \mathrm{~cm}$ in upstream or downstream part (Fig.1). The stream bed and water surface elevation are measured by a digital point gauge at 140 points over monitoring domain, which means there are 10 measured points in every cross section.

\section{(2) Experimental Runs}

The response of different amplitude and discharges are studied. The experiments are conducted for the conditions as shown in Table 1. Six cases to discharge change are set. The discharges of Case ${ }^{*}-1,2,3$ and 4 are almost fixed . Case*-5 is maximum inflow discharge under no

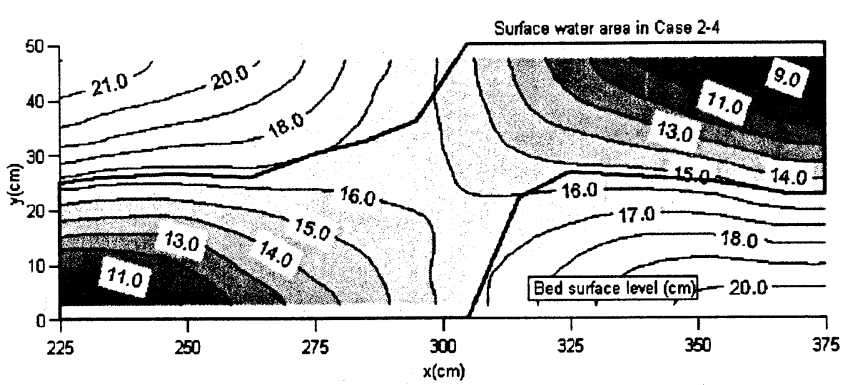

Fig. 2 Bed shape contour in Case 2

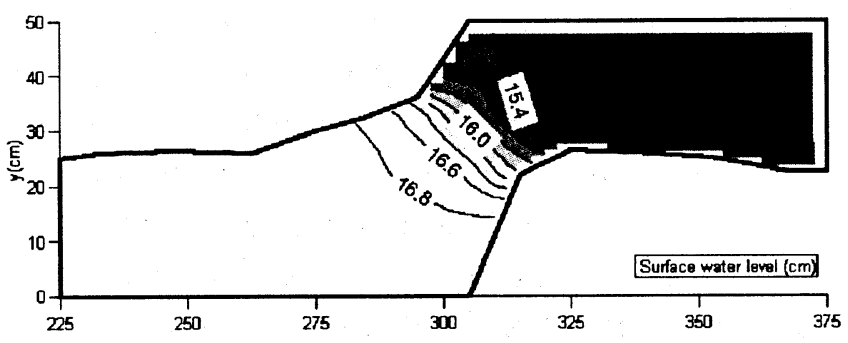

Fig. 3 Surface water level contour in Case 2-4

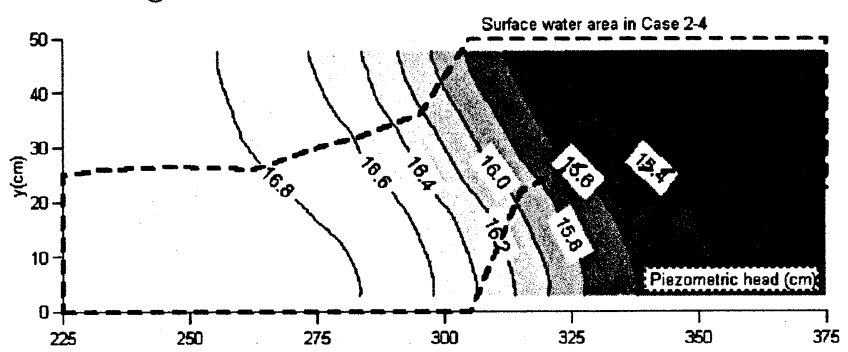

Fig. 4 Subsurface piezometric head contour in Case 2-4

flow condition. Case*-6 is for almost half discharge of Case*-5.

\section{(3) Estimation of total SSF flux}

Subsurface flow distribution in the sandbar and possible locations of interactions with the stream flow have been recognized by the experimental investigations (Ahmed et al. 2000). But the research is on exchange between "surface water area" and "sandbar area" at horizontal viewpoint. When we discuss longitudinal surface water discharge profile, flux evaluation in surface water area and subsurface water area is needed at "cross-sectional viewpoint". Usually surface water flux should be calculated by measuring velocity profile. But surface water depth in experiment flume is too shallow to measure velocity profiles. Then we estimate subsurface water flux $Q_{s s F}$ at arbitrary cross-section, and then surface water discharge $Q_{S F}$ is estimated from difference between total discharge $Q_{\text {tot }}$ and $Q_{S S F}$.

Assume that the bed material is isotropic, $Q_{S S F}(x)$ can be expressed as Eq. (2).

$$
Q_{S S F}(x)=\int_{y=0}^{y=B} q_{x}(x, y) d y,
$$




$$
\begin{aligned}
& q_{x}(x, y)=D(x, y) \cdot u_{x}(x, y) \\
& u(x, y)=-k \frac{\partial h(x, y)}{\partial x}
\end{aligned}
$$

where $Q_{S S F}(x)$ is the total subsurface water flux through the whole cross-section at $x=x ; y$ is the transverse distance (at $x=x$ ) from right wall $(y=0)$ to left wall $(y=B)$; and $q_{x}$ is the subsurface water flux per unit width; $u_{x}$ is the Darcy velocity; $h(x, y)$ is piezometric head and $\mathrm{k}$ is hydraulic conductivity. $D(x, y)$ is the thickness of subsurface water flow. $D$ equals $z_{b}$ at the position where surface water flow exists, and equals $h(x, y)$ at the position where surface is dry. So, the discretized form of Eq.(2) can be written as Eq.(3).

$$
\begin{aligned}
Q_{S S F}(x) & =\sum_{j=1}^{N_{\mathcal{L}}} q_{x j}(x) \Delta y \\
= & \sum_{j=1}^{N_{j}} D_{j}(x) k\left\{h_{j}\left(x-\frac{\Delta x}{2}\right)-h_{j}\left(x+\frac{\Delta x}{2}\right)\right\} \frac{\Delta y}{\Delta x}
\end{aligned}
$$

where, $h_{j}$ is the subsurface water level at $j$ th node corresponding to $y=j \Delta y ; \Delta x$ and $\Delta y$ are the incremental distance in $x$ and $y$ directions respectively; $j=1 . . . N_{j}$ is the $j$ th node in $y$-axis. $N_{j}$ is 10 for this experiment, because $\Delta y$ is $5 \mathrm{~cm} . \Delta x$ is $10 \mathrm{~cm}$ or $15 \mathrm{~cm}$ as shown in Fig.1.

\section{RESULTS AND DICUSSION}

\section{(1) Interpretation of Phenomenon in Case 2-4}

Case2-4 is selected as a standard case in order to show the fundamental phenomena. Bed shape contour is shown in Fig.2 according to Eq.(1). Measured profiles of surface water level and subsurface water piezometric head are shown in Fig.3 and Fig.4. In Fig.3, water level difference between two pools is determined by average bed slope and the longitudinal wavelength of bed shape. The difference is almost $L_{f} I_{s} / 2=1.5 \mathrm{~cm}$ in this experiment. In Fig.4, piezometric head has longitudinal gradient between two pools and less gradient near the pools. Near the riffle transverse gradient occur in sandbar shown by Ahmed and short-cut flow go through upstream area in sandbar. In upstream and downstream pool area, surface water level and piezometric head in subsurface water are almost the same. This indicates that

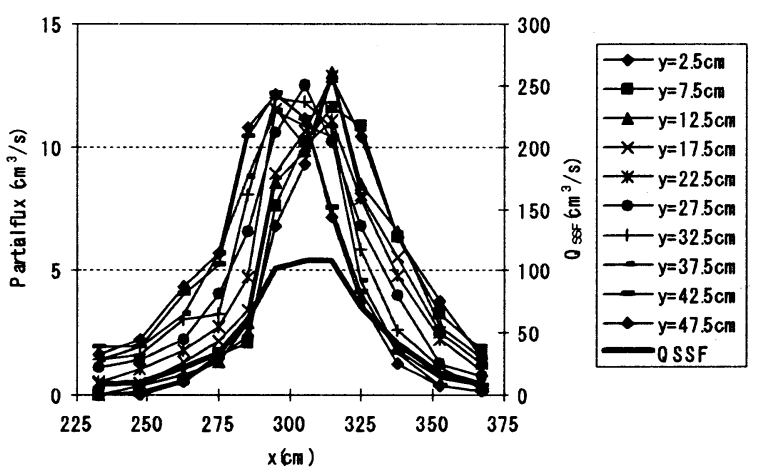

Fig. 5 Longitudinal profile of $q_{x j} \Delta y$ and $Q_{S S F}$ in Case 2-4

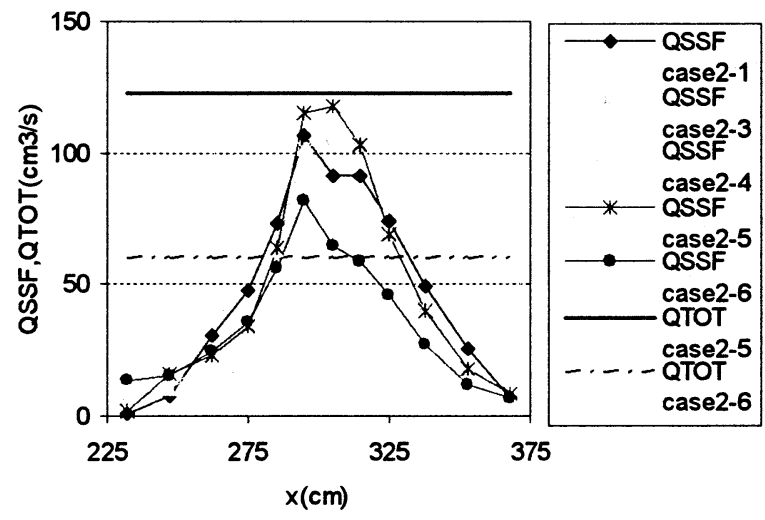

Fig. 6 Longitudinal profile of $Q_{S S F}$ in Case 2-1 to 2-6

surface water levels in two pools control subsurface water flow's upstream and downstream boundary.

Fig. 5 shows longitudinal profile of $q_{x j} \Delta y$ and $Q_{S S F}$ in Case 2-4 calculated by Eq. (3). $q_{x j} \Delta y$ is almost corresponding to longitudinal gradient of piezometric head in Fig. 4 because $q_{x}$ is the product of Darcy flux $u_{x}$ and $D$. By summation of $q_{x j} \Delta y$, total subsurface water flux $Q_{S S F}$ increases in upstream area, and there is a mild peak in riffle area. This peak value of $Q_{S S F}\left(Q_{S S F \max }\right)$ determines minimum surface water discharge $Q_{S F m i n}=Q_{t o t}$ $Q_{\text {SSFmax }}$, which is strongly related to minimum discharge or environmental discharge. In this case, total flow $Q_{\text {tot }}$, subsurface flow $Q_{\text {SSFmax }}$ and surface flow $Q_{S F m i n}$ are 348,108 and $240 \mathrm{~cm}^{3} / \mathrm{s}$ respectively.

\section{(2) Response by total discharge change}

Fig.6 shows longitudinal profile of $Q_{\text {SSFmax }}$ in Case $2-1$ to 2-6. In this study, "Critical discharge" is defined as the maximum inflow discharge, which is under no surface flow condition. In the bed shape condition $a=6.4 \mathrm{~cm}$, critical discharge is $123 \mathrm{~cm}^{3} / \mathrm{s}$ (Case2-5). In this condition, the estimated $Q_{S S F}$ and 


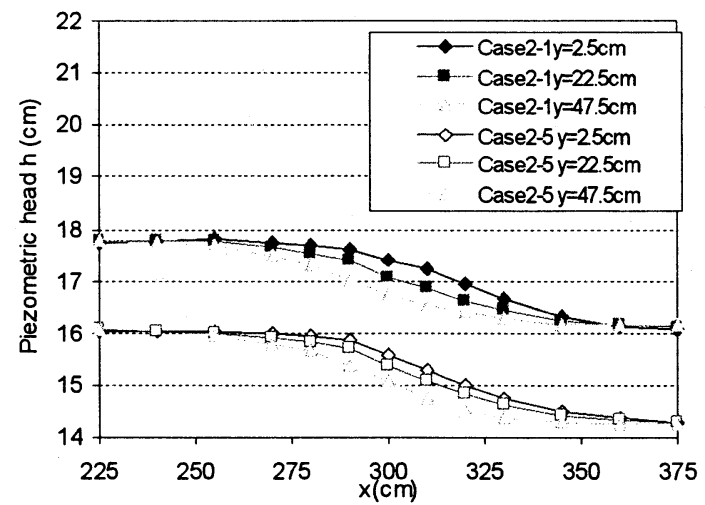

Fig. 7 Longitudinal profile of $h$ in Case 2-1 and 2-5

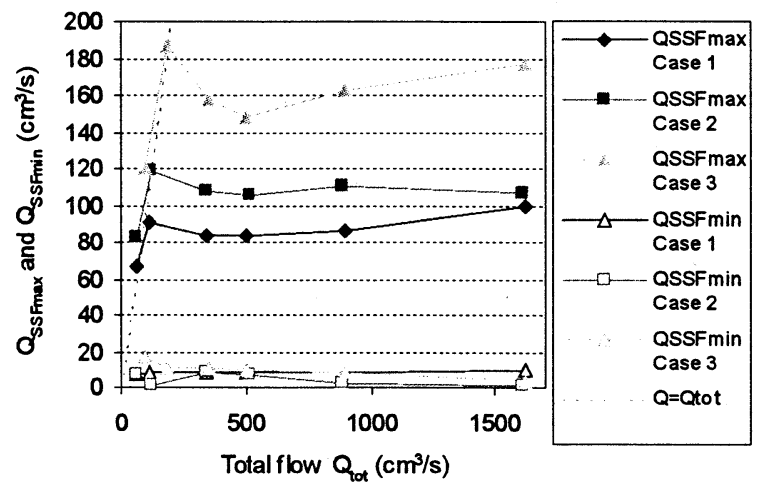

Fig. $8 Q_{S S F \max }$ and $Q_{S S F m i n}$ to total inflow $Q_{t o t}$

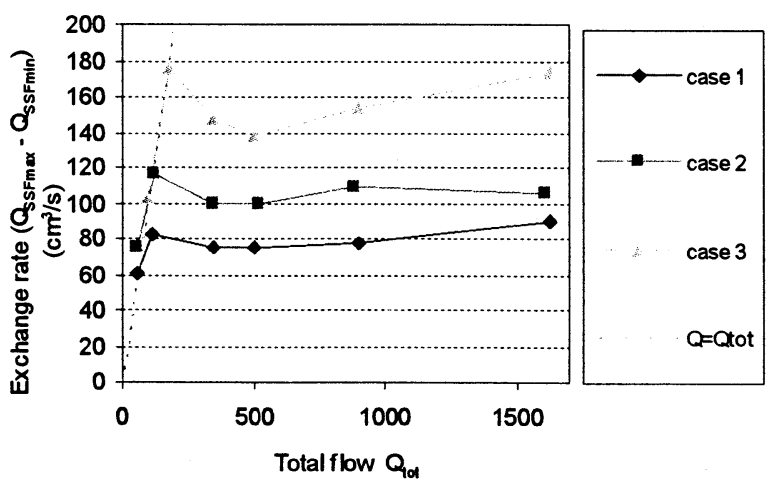

Fig. 9 Exchange rate to total inflow $Q_{\text {tot }}$

the given total discharge are almost the same. This indicates that estimating method of $Q_{S S F}$ assuming Dupuit-Forchheimer flow is reasonable. It is shown in the figures when the discharge is larger than the critical discharge, profile of $Q_{S S F}$ and the value of $Q_{\text {SSFmax }}$ are fixed. Fig.7 shows the difference in longitudinal piezometric head profile between case 2-1 and case 2-5. Although the value of piezometric head increases with discharge rise slightly, profile shape and gradient of head are similar. This phenomenon gives constant $Q_{S S F}$ profile in Fig.6. Trend in Fig. 6 indicates that while surface water

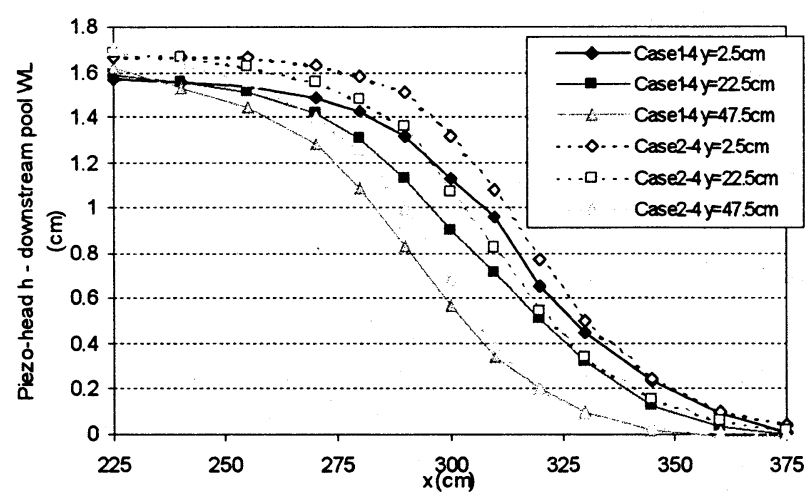

Fig. 10 Relative height of piezometric head from water level of downstream pool

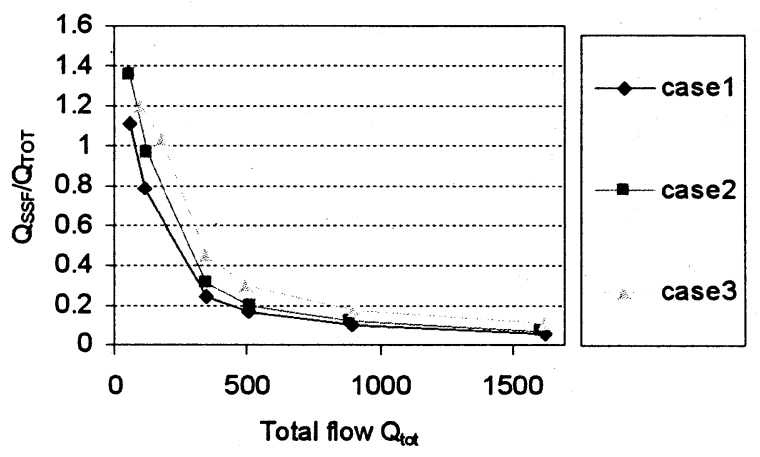

Fig. 11 Ratio of subsurface flux to total discharge

exists, exchange flux between surface water and subsurface water on riffle part is stable. Exchange flux can be evaluated from $Q_{\text {SFmax }}-Q_{\text {SFmin }}=Q_{\text {SSFmax }}$ $Q_{\text {SSFmin, }}$ but $Q_{\text {SSFmin }}$ is very small. Then $Q_{\text {SSFmax }}$ represents the trend of exchange flux. Discussed trend is shown in Fig.8 and Fig.9.

\section{(3) Response by bed amplitude change}

Fig.8 shows $Q_{\text {SSFmax }}$ and $Q_{\text {SSFmin }}$ in all bed shape cases. Exchange rate between surface water and subsurface water is calculated.(Fig.9). In each bed shape, $Q_{\text {SSFmax }}$ is almost constant when total discharge is larger than critical discharge. The value of $Q_{\text {SSFmax }}$ is larger for higher bed amplitude. In Fig.10, longitudinal relative height profile of piezometric head from downstream pool level in Case 1-4 and Case 2-4 are shown. Case 2-4 has higher bed amplitude which leads to higher gradient. This was caused by surface water condition, which supply the boundary condition for subsurface water flow at 3-D point of view. Therefore, higher Darcy flux occurs with higher gradient in higher amplitude cases.

As the result of above phenomena, ratio of 
subsurface flux to total discharge is calculated shown in Fig.11. Subsurface water flux is fixed as already shown in Fig.8, then ratio is easily known when we estimate $Q_{\text {SSFmax }}$.

\section{CONCLUSIONS}

The effect of bed amplitude on the interaction between surface and subsurface water flowing in a river with alternate sandbars has been investigated by experiment. It is revealed that bed shape has significant effect on surface and subsurface water exchange distribution. Normally, it is believed that if we increase the discharge from the upstream, the gradient of the surface and subsurface flow will increase, and the leakage from the surface flow to subsurface flow will increase accordingly. However, due to the experiment results, it is found that the potential gradient of subsurface flow does not change with the upstream discharge when the given total flow is larger than the "critical discharge". This phenomenon means that if this exchange flux which is represented by $Q_{\text {SSFmax }}$, and minimum surface water discharge determined from the riparian ecosystem are known, total discharge required to be supplied from upstream can be determined.

On the other hand, bed shape controls exchange rate strongly. In higher bed amplitude cases, steady value of $Q_{\text {SSFma }}$ is larger, and this indicates bed shape has an effect on subsurface condition by affecting the surface condition, which is the subsurface boundary condition. As the amplitude increases the potential gradient increases correspondingly. For lower amplitude condition, the distance between pools is longer, and the potential gradient is milder. For higher amplitude the distance between pools is shorter, which makes the potential gradient steeper. In the determination of the required total upstream discharge leakage flux should be evaluated. From the discussion above, we should put more emphasis on effect of the bed shape instead of the effect of total discharge change to leakage flux.

This study is limited in reach scale, especially the area with sandbars and channel. To develop the water management technique, more study is needed at the viewpoint of segment scale, including water interaction between reach scale area and the ground water in the wide plain area.

\section{REFERENCES}

1)Freeze, R. A. and P. A. Witherspoon: Theoretical analysis of regional groundwater flow, 2, The effect of water table configuration and subsurface permeability variations, Water Resour. Res., 3, pp.623-634, 1967.

2)Freeze, R. A. and P. A. Witherspoon: Theoretical analysis of regional groundwater flow, 2, Quantitative interpretations, Water Resour. Res., 4(3), pp.581-590, 1968.

3)Harada, M. and F. Takagi: A study on seepage process of river water into sedimentary layer of valley and decrease of channel discharge (in Japanese), Journal of Hydraulic, Coastal and Environmental Engineering, 533 (II-34), pp.2130, 1996

4)Larkin, R. J. and J. M. Sharp: On the relationship between river basin geomorphology, aquifer hydraulics, and groundwater flow direction in alluvial aquifers, Geol. Soc. Am. Bull., 104, pp.1608-1620, 1992.

5)Harada, M., K. Okajima and T. Yamada: Interaction process between stream and aquifer in the Yasugawa alluvial fan (in Japanese), Annual J. of Hydraulic Engg. , JSCE, Vol. 48, pp.385-390, 2004.

6)Sumi, T., U. Ebara and T. Tsujimoto: On the sub-surface flow and water exchangerate through temporally ponds on a sandbar (in Japanese), Advances in River Engg, JSCE, Vol.6,

7)Ahmed, A. M. M. M., T. Sumi and T. Tsujimoto: Subsurface flow in a stream with alternate sandbars, Annual $J$. of Hydraulic Engg., JSCE, Vol. 45, pp 349-355, 2001.

(Received September 30, 2004) 